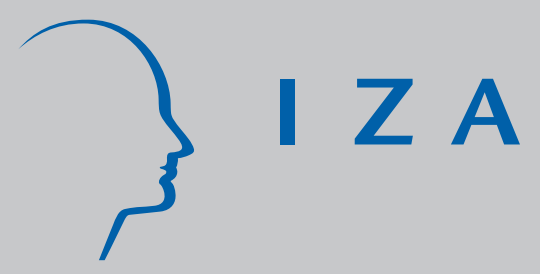

IZA DP No. 585

Human Capital Formation, Life Expectancy and the Process of Economic Development

Matteo Cervellati

Uwe Sunde

September 2002 


\title{
Human Capital Formation, Life Expectancy and the Process of Economic Development
}

\author{
Matteo Cervellati \\ Universitat Pompeu Fabra, Barcelona \\ Uwe Sunde \\ IZA Bonn and University of Bonn
}
Discussion Paper No. 585
September 2002

(updated November 2004 - old version available at ftp://ftp.iza.org/dps/dp585 ov.pdf)

\author{
IZA \\ P.O. Box 7240 \\ D-53072 Bonn \\ Germany \\ Tel.: +49-228-3894-0 \\ Fax: +49-228-3894-210 \\ Email: iza@iza.org
}

This Discussion Paper is issued within the framework of IZA's research area Welfare State and Labor Market. Any opinions expressed here are those of the author(s) and not those of the institute. Research disseminated by IZA may include views on policy, but the institute itself takes no institutional policy positions.

The Institute for the Study of Labor (IZA) in Bonn is a local and virtual international research center and a place of communication between science, politics and business. IZA is an independent, nonprofit limited liability company (Gesellschaft mit beschränkter Haftung) supported by the Deutsche Post AG. The center is associated with the University of Bonn and offers a stimulating research environment through its research networks, research support, and visitors and doctoral programs. IZA engages in (i) original and internationally competitive research in all fields of labor economics, (ii) development of policy concepts, and (iii) dissemination of research results and concepts to the interested public. The current research program deals with (1) mobility and flexibility of labor, (2) internationalization of labor markets, (3) welfare state and labor market, (4) labor markets in transition countries, (5) the future of labor, (6) evaluation of labor market policies and projects and (7) general labor economics.

IZA Discussion Papers often represent preliminary work and are circulated to encourage discussion. Citation of such a paper should account for its provisional character. A revised version may be available on the IZA website (www.iza.org) or directly from the author. 
IZA Discussion Paper No. 585

September 2002 (updated November 2004)

\section{ABSTRACT \\ Human Capital Formation, Life Expectancy and the Process of Economic Development ${ }^{*}$}

This paper provides a unified theory of the transition in income, life expectancy, education and population, experienced by the Western world when passing from an environment of economic stagnation to sustained growth. The transition is based on the interplay between human capital formation, technological progress, and life expectancy. A positive feedback between human capital accumulation and longevity is eventually triggered when endogenous skill-biased technological progress provides sufficiently high returns to human capital for large fractions of the population to outweigh the costs in terms of lifetime spent on education.

JEL Classification: E10, J10, O10, O40, O41

Keywords: long-term development, endogenous life expectancy, heterogeneous human capital, technological progress, industrial revolution

Corresponding author:

Uwe Sunde

Institute for the Study of Labor (IZA)

PO Box 7240

53072 Bonn

Germany

Email: sunde@iza.org

\footnotetext{
* The authors would like to thank Giuseppe Bertola, Antonio Ciccone, Oded Galor Adriana Kugler, Matthias Messner, Omer Moav, Joel Mokyr, Omar Licandro and Nicola Pavoni, Richard Rogerson and two anonymous referees for very helpful comments and suggestions, as well as participants at ASSET 2002, Cyprus, the RES Conference 2003, Warwick, the Minerva Conference on the Transition from Stagnation to Growth, Rorschach, the EEA Meetings 2003, and seminar participants at the Universities Bologna, Bonn and European University Institute, Florence, for very helpful discussions. Financial support from German Research Foundation DFG, and IZA is gratefully acknowledged. All errors are our own.
} 
From the second half of the 18th Century onwards, the Western world experienced unprecedented changes in the economic environment and in virtually all other aspects of human life. After continued stagnant development, aggregate and per capita incomes entered a path of rapid and sustained growth as depicted in Figure 1(a). At the same time, the living conditions also changed radically. Mortality fell and average life expectancy at birth as well as at later ages, which had virtually been unchanged for millennia, increased significantly within just a few generations, see Figure 1(b). Simultaneously, the traditional social environment changed profoundly, as the vast majority of the population became educated. Literacy, which used to be the privilege of a small elite, became widespread among the population, as is illustrated in Figure 1(c) by the population share able to sign documents. While almost all skills were acquired through apprenticeships before the industrial revolution, formal schooling represents the main channel of human capital formation afterwards. ${ }^{1}$ Also the size of the population increased substantially (Figure 1(d)). ${ }^{2}$ This increase seems to have been mainly driven by increased longevity, rather than changed fertility behavior. ${ }^{3}$ While GDP kept growing unboundedly after the transition, the growth in life expectancy and population eventually attenuated.

The aim of this paper is to provide a theory explaining this transition in income, life expectancy, education and population size as the endogenous outcome of a gradual process of development. Earlier contributions to the literature have concentrated on the existence of multiple steady state equilibria and have explained the transition from a stagnant regime to an environ-

\footnotetext{
${ }^{1}$ This is reflected in the substantial increase in average years of schooling and the age when individuals started working, that accompanied the transition, see Cipolla (1976), Maddison (1991) and Galor and Weil (2000).

${ }^{2}$ The stylized facts are illustrated in Figure 1 with data for Great Britain, but other European countries exhibit similar patterns. The GDP per capita data in Figure 1(a) are taken from Maddison (1991) and refer to United Kingdom excluding South Ireland. Missing intermediate values are obtained by linear interpolation. The data for life expectancy in England and Wales, see Figure 1(b), are taken from Www.Mortality.Org (2002) and Floud and McCloskey (1994). The literacy data in Figure 1(c) reflect the ability to sign marriage documents, a measure of intermediate literacy skills, which roughly corresponds to the proportion of the population able to read fluently (Schofield, 1973, p. 440). The data are taken from Schofield (1973) and West (1978), and pertain to England and Wales. Note that writing skills are essential for acquiring other skills like arithmetic or other substantive knowledge, see also Cipolla (1969) and Floud and McCloskey (1994). The population size data in Figure 1(d) are taken from Maddison (1991) and refer to the U.K. excluding South Ireland.

${ }^{3}$ See Johnson (2000). Galor (2004) provides an extensive discussion and further empirical evidence on the relationship between fertility, longevity and population growth.
} 


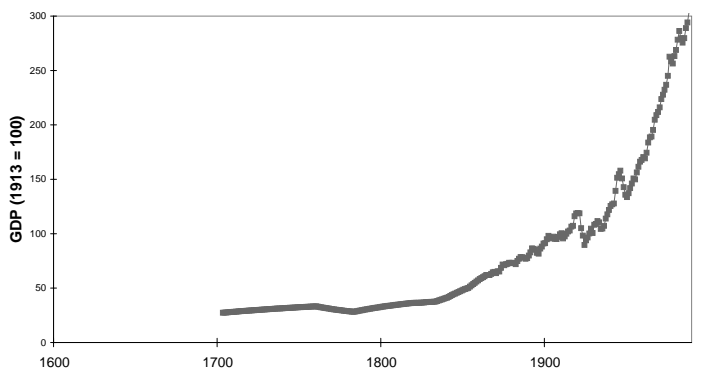

(a) GDP per capita (U.K.)

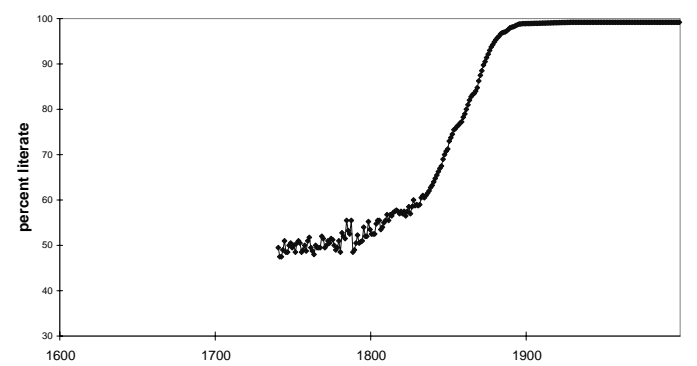

(c) Literacy Levels (England and Wales)

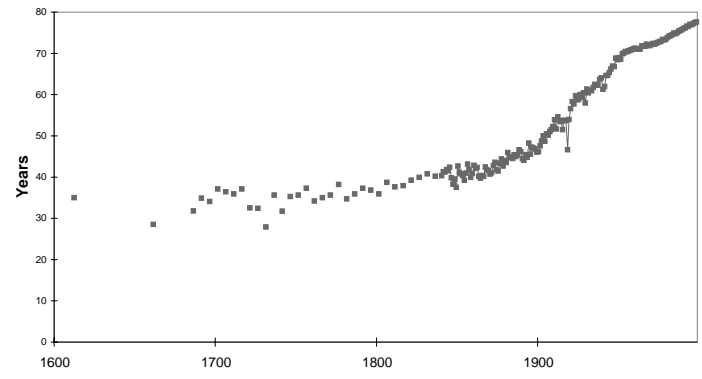

(b) Life Expectancy (England and Wales)

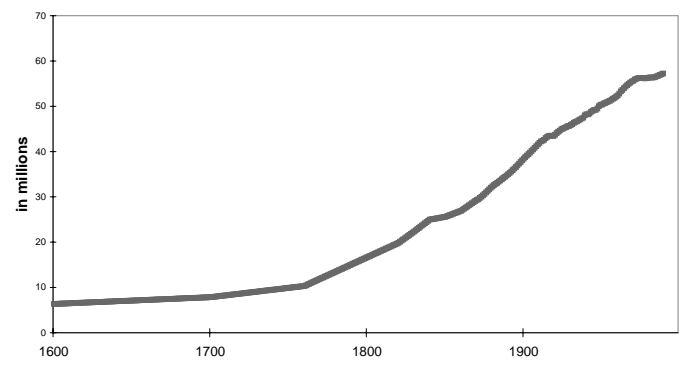

(d) Population Size (U.K.)

Figure 1: The Stylized Facts of Long-Run Development

ment of sustained growth by scale effects, exogenous technological change, or shocks that move the dynamic system from one steady state to another. ${ }^{4}$ The historical observation of gradual development leading to a rapid transition has proved difficult to reconcile with this approach, however. This paper characterizes both the stagnant and the growth regimes within a single framework and analyzes the endogenous transition between these regimes. In particular, we explain the phase transition within a unique dynamic system whose qualitative features change gradually and endogenously. In this respect, our paper contributes to the recent literature of unified theories initiated by Galor and Weil (2000) and Galor and Moav (2002). These theories are based on a feedback mechanism between technology and human capital and demonstrate a transition that is triggered by endogenous fertility behavior and endogenous human evolution,

\footnotetext{
${ }^{4}$ Early studies describing the correlation between the economic and the demographic transition include Komlos and Artzouni (1990), and Kremer (1993). Population growth induces an industrial revolution via increased specialization in the model by Goodfriend and McDermott (1995), and by facilitating the generation of knowledge in Jones (2001). Exogenous technological progress moves the labor force from agricultural to industrial production in Hansen and Prescott (2002). An exogenous reduction in mortality triggers the transition in Boucekkine, de la Croix, and Licandro (2003). See also Galor (2004) for an overview of the literature.
} 
respectively. Complementary to these unified theories, we provide a novel mechanism driving the transition, which is based on a positive feedback loop between life expectancy, human capital formation, and endogenous technological progress. ${ }^{5}$

Our theory rests on the idea that human capital is a central factor of production, and at the same time helps to improve the longevity and productivity of future generations. In turn, individuals make their decisions concerning human capital acquisition by taking their life expectancy as well as the economic environment into account. At the individual level, becoming educated is costly in terms of time, which induces a complementarity between the returns to human capital and the remaining lifetime available to enjoy those returns. Human capital-driven technological progress reinforces this complementarity. This leads to a potential virtuous circle of more human capital formation, higher life expectancy, and faster growth. We show that even a very slow rate of endogenous skill biased technological progress can induce a positive feedback loop between human capital formation and longevity. As long as the constraint of low life expectancy is binding and technology is not sufficiently advanced, however, the economy is trapped on a low growth path. Economic improvements and improvements in life expectancy are miniscule and almost undetectable for a very long period. But these improvements eventually lead to the disappearance of the stagnant regime and trigger a rapid transition towards sustained growth and improved living conditions. The transition occurs only when longevity and technology ensure sufficiently high returns to human capital for a large fraction of the population. This approach has the advantage of being based on observable variables like longevity and schooling, as compared to theories resting on feedback mechanisms between technology and human capital, which are more difficult to measure empirically. ${ }^{6}$

The paper is organized as follows. In section 1 we describe the economic environment, we state and solve the individual education problem and describe the dynamic links between generations. Section 2 characterizes the development process and contains an illustrative simulation of the model. Section 3 concludes. All proofs are collected in the appendix.

\footnotetext{
${ }^{5}$ We abstract from endogenous fertility behavior. For contributions studying the role of fertility for long-term development and the demographic transition, see Kogel and Prskawetz (2001), Hazan and Berdugo (2002), Lucas (2002), Kalemli-Ozcan (2002), Lagerlof (2003) and Doepke (2004), among others.

${ }^{6}$ The available empirical evidence regarding our assumptions and central results is discussed below.
} 


\section{The Model}

Time is continuous and denoted by $\tau \in \mathbb{R}^{+}$. The economy is populated by a discrete number of overlapping generations, indexed by $t \in \mathbb{N}$. Each generation $t$ consists of a unit mass of individuals, who share a common life expectancy $T_{t} \in \mathbb{R}^{+}$(the determinants of which will be discussed below) and have different abilities $a$. For each generation, abilities are distributed uniformly over $[0,1] .{ }^{7}$ Every member of a generation gives birth to one offspring at age $l>0$. Figure 2 illustrates the timing of the model for the case in which life expectancy is increasing over the course of generations. The total size of the population is given by the number of generations alive at any moment in time $\tau$. Consequently, despite the assumption of constant fertility, which is made to highlight the role of longevity, the model generates population dynamics due to varying life expectancy. ${ }^{8}$

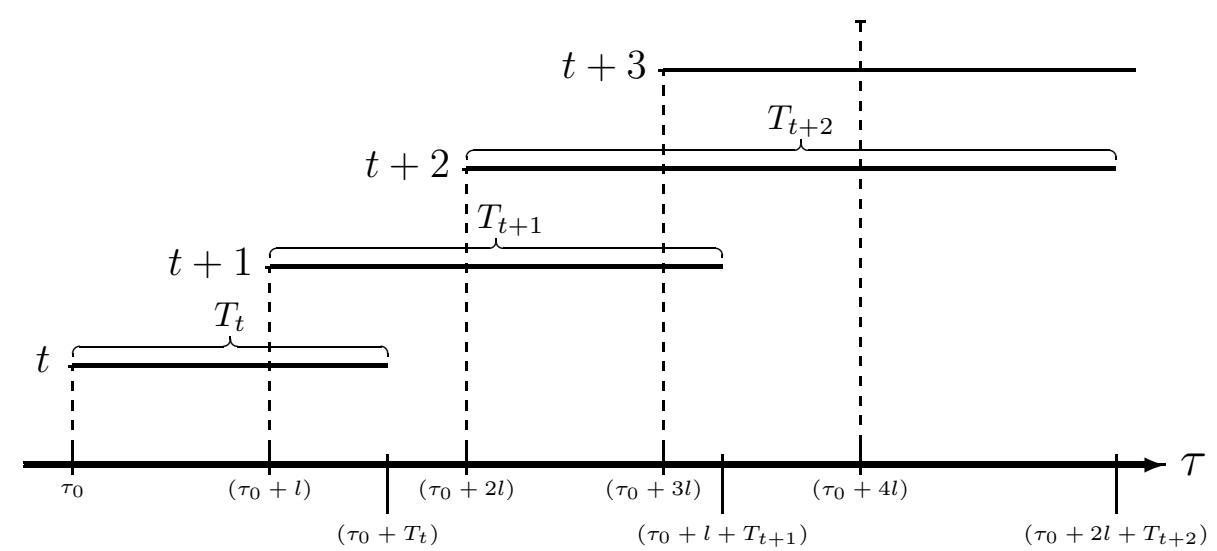

Figure 2: Timing and the Evolution of Generations

\section{A Human Capital Formation}

Before supplying labor in order to earn an income and consume, individuals have to decide about their education. At their birth they are endowed with one unit of unskilled labor which requires

\footnotetext{
${ }^{7}$ We assume that the ex ante distribution of innate ability or intelligence does not change over the course of generations. The uniform distribution is chosen for simplicity, but the results can be obtained with an arbitrary distribution of ability, including the case in which all agents are equally able.

${ }^{8}$ The timing of fertility is of no relevance for the main argument because, as clarified below, the dynamics of the economy do not depend on the age structure of the population. If fertility timing were linked to life expectancy, population dynamics would disappear only in the limit case of $l_{t}=T_{t}$ for any $t$.
} 
no education and can be supplied immediately to the market. Alternatively, individuals may become skilled through the acquisition of human capital, which is characterized by a high content of abstract knowledge and facilitates innovation and the development of new ideas. ${ }^{9}$ Every generation has to build up its stock of human capital from zero, since the peculiar characteristic of human capital is that it is embodied in people. To focus on changes in the environment, which create the necessary and sufficient conditions for large parts of the population to acquire human capital, we abstract from any real resources as input in education, from public provision of education, and exclude any link between generations, through savings or bequests. Individuals themselves, rather than their parents, decide about their education. Our central contention is that the choice of human capital acquisition involves a trade-off: it enables individuals to earn skilled labor wages but its acquisition requires valuable lifetime. ${ }^{10}$ More precisely, consider a generation $t$ of individuals endowed with life expectancy $T_{t}$. Unskilled workers can earn their wage for all their lifetime $T_{t}{ }^{11}$ Alternatively, at the beginning of their lives, individuals can decide to acquire human capital by means of a time consuming education process, which allows them to supply skilled labor albeit only after the education process is completed. Hence, on the individual level, the trade-off between acquiring human capital or remaining unskilled, amounts to the decision whether or not to spend a fix cost $e$ in terms of time exclusively on education. The amount of human capital acquired through the education process depends on innate ability. Individuals with larger ability benefit more from education and acquire more human capital. We assume that an agent with ability $a$ acquires $a$ effective units of skilled labor which can be supplied on the market during the remaining lifetime: $T_{t}-e$. In contrast, every individual, regardless of his ability, can supply one unit of unskilled labor throughout his entire life. This formulation captures two crucial features of the human capital formation process. First, longer life expectancy makes acquiring human capital relatively more attractive for individuals of any

\footnotetext{
${ }^{9}$ Hassler and Rodriguez-Mora (2000) use a related perception of skilled versus unskilled labor.

${ }^{10}$ Moav (2005) points out that in a standard endogenous fertility model, changes in longevity do not affect investment in education made by parents in their children, but argues that longer life expectancy would still lead individuals to increase their own human capital. Hazan and Zoabi (2004) offer an alternative approach for how improvements in health and longevity may bring about changes in education decisions of parents concerning their offspring.

${ }^{11}$ Wage rates for the different types of labor are determined competitively on the labor market, see below.
} 
level of ability. Second, higher innate ability, which is less important for providing manual labor, facilitates the acquisition of human capital. ${ }^{12}$ The choice of human capital acquisition is made optimally at the individual level, taking endowments in terms of life expectancy and ability, as well as market wages, as given. These individual choices determine the human capital structure at the aggregate level.

\section{B Production and Labor Market Equilibrium}

The stocks of skilled and unskilled labor available in the economy are the only factors of production. A unique final consumption good is produced by two sectors. These sectors structurally differ with respect to the intensity with which they use skilled and unskilled labor, and their total factor productivity (TFP). The skilled-labor intensive sector is denoted by $\mathcal{H}$, and the unskilled-labor intensive sector is denoted by $\mathcal{L}$. We adopt a simple vintage model in which technological vintages are characterized by different levels of TFP and are generation-specific. This implies that a given generation $t$ can only operate technologies of vintage $t$. Therefore, to determine the labor market equilibrium, we can concentrate attention on the production process of a given generation $t$. The production technologies available to generation $t$ in sector $\mathcal{L}$ and $\mathcal{H}$ are denoted by $Y_{t}^{\mathcal{L}}$ and $Y_{t}^{\mathcal{H}}$. We consider a Cobb-Douglas specification of the sectoral production functions and, for the sake of simplicity, we restrict attention to the extreme case in which every sector uses only one type of labor. Denote TFP characterizing vintage $t$ in the $\mathcal{H}$-sector and in the $\mathcal{L}$-sector by $A_{t}^{\mathcal{H}}$ and $A_{t}^{\mathcal{L}}$, respectively, and the ratio of the two as $A_{t} \equiv A_{t}^{\mathcal{H}} / A_{t}^{\mathcal{L}}$. The production function of generation $t$ is then given by

$$
Y_{t}=Y_{t}^{\mathcal{L}}+Y_{t}^{\mathcal{H}}=A_{t}^{\mathcal{L}} L_{t}^{\alpha}+A_{t}^{\mathcal{H}} H_{t}^{\alpha}
$$

where $\alpha \in(0,1) .{ }^{13} L_{t}$ and $H_{t}$ denote the aggregate levels of unskilled and skilled labor supplied by generation $t$. Denote the instantaneous wage rates paid to every unit of skilled and unskilled labor supplied by generation $t$ by $w_{t}^{H}$ and $w_{t}^{L}$, respectively. Wage rates are determined in the

\footnotetext{
${ }^{12}$ Any alternative model of human capital formation reproducing these two features would be entirely equivalent for the purpose of this paper. For example, individual ability could affect the costs of the education process instead of its return. Alternative settings like on-the-job learning could similarly be used to illustrate the importance of longevity for human capital formation.

${ }^{13}$ Different productivity parameters $\alpha^{\mathcal{H}}$ and $\alpha^{\mathcal{L}}$ in the two sectors would not alter our qualitative results.
} 
competitive labor market and equal marginal productivities, ${ }^{14}$

$$
w_{t}^{H}=\frac{\partial Y_{t}}{\partial H_{t}}=\alpha A_{t}^{\mathcal{H}} H_{t}^{\alpha-1}, \text { and } w_{t}^{L}=\frac{\partial Y_{t}}{\partial L_{t}}=\alpha A_{t}^{\mathcal{L}} L_{t}^{\alpha-1}
$$

Since technological progress occurs in the form of the arrival of new vintages of technology, the productivity of, and therefore the corresponding wages earned by, individuals of generation $t$ operating vintage $t$ do not change during their lifetime. ${ }^{15}$

Individuals belonging to a given generation $t$ have to decide whether to spend the time $e$ on acquiring human capital and supplying skilled labor for the remaining $T_{t}-e$ of their lifetime, or whether to supply unskilled labor for their entire life. Individuals' utility is linear in consumption and there is no discounting. Hence, utility maximization implies maximization of total lifetime earnings. Timing issues within generation $t$ are of no relevance, so we abstract from them. When making their decision, individuals take life expectancy $T_{t}$ as well as the wages accruing for each type of labor as given. Individuals choose the type of labor that maximizes their lifetime income stream. The latter is given by the competitive wage that can be earned by supplying either one unit of unskilled labor or $a$ units of skilled labor acquired through education. Denote the total lifetime income for an individual of generation $t$ with ability $a$ by $V_{t}^{L}(a)$ if remaining unskilled,

\footnotetext{
${ }^{14}$ Empirical evidence supports the view that different sectors competed for labor, and wage payments reflected producitivities even at early stages of industrial development, see e.g. Magnac and Postel-Vinay (1997). In the benchmark case with only one factor in each sector, this assumption implies decreasing returns to scale with factor payments not exhausting income. Assuming that non-wage income is divided equally among all individuals, setting wages to average productivity, or introducing fixed factors like land in both sectors would be equivalent assumptions to ensure that all income is appropriated without affecting education decisions, which are the focus of this paper.

${ }^{15}$ The non-substitutability of inputs between vintages, and that only the latest vintages are adopted, are in line with e.g. Malcomson (1975). This implies that e.g. a mechanic in the late 20th century knows how to repair a common rail diesel engine, but not a steam engine. However, as will become clear in subsection D, vintages build upon the advances of previous vintages, i.e. common rail diesel engines incorporate technological principles that partly derive from steam engines. Note that this vintage structure implies that different vintages of technology are operated at the same moment in time, $\tau$, by different generations of individuals alive at $\tau$. Technological vintages go out of use and become passive once the individuals working on it die. This reflects the idea that new generations find it more profitable to use new, more productive vintages of technology than to revive old ones.
} 
and by $V_{t}^{H}(a)$ if acquiring human capital. Then,

$$
\begin{aligned}
V_{t}^{L}(a) & =\int_{0}^{T_{t}} w_{t}^{L} d \tau=T_{t} w_{t}^{L}, \\
V_{t}^{H}(a) & =\int_{e}^{T_{t}} a w_{t}^{H} d \tau=a\left(T_{t}-e\right) w_{t}^{H} .
\end{aligned}
$$

As anticipated, acquiring human capital is relatively more profitable the larger an individual's expected lifetime, and the higher his ability. Since an agent is indifferent whether or not to acquire human capital if $V^{H}$ and $V^{L}$ are equal, we can identify a unique ability threshold,

$$
\tilde{a}_{t}=\frac{T_{t}}{\left(T_{t}-e\right)} \frac{w_{t}^{L}}{w_{t}^{H}}
$$

for which $V_{t}^{L}\left(\tilde{a}_{t}\right)=V_{t}^{H}\left(\tilde{a}_{t}\right)$. Individuals with $a>\tilde{a}$ find it profitable to incur the cost and acquire human capital, while those with $a<\tilde{a}$ prefer to remain unskilled. The aggregate levels of skilled labor $H_{t}$ and unskilled labor $L_{t}$ depend on the fraction of individuals of the given generation $t$ that decides to become educated. Consequently, the aggregate supplies of both types of labor by generation $t$ are

$$
L_{t}=\int_{0}^{\tilde{a}_{t}} d a=\tilde{a}_{t} \quad \text { and } \quad H_{t}=\int_{\tilde{a}_{t}}^{1} a d a=\frac{1-\tilde{a}_{t}^{2}}{2}
$$

We are now in the position to characterize the labor market equilibrium for each generation $t$. This equilibrium is characterized by wage levels $w_{t}^{H}$ and $w_{t}^{L}$, and the corresponding fraction of individuals acquiring human capital $\lambda_{t} \equiv\left(1-\tilde{a}_{t}^{*}\right)$, such that no individual has an incentive to change his education decision.

Definition 1. [LABOR MARKET EQUILIBRIUM] The labor market equilibrium for generation $t$ is characterized by a vector

$$
\left\{w_{t}^{H *}, w_{t}^{L *}, \tilde{a}_{t}^{*} \equiv\left(1-\lambda_{t}\right)\right\}
$$

such that, for any given $T_{t}$, conditions (2), (5) and (6), are simultaneously satisfied.

The relationship between life expectancy $T_{t}$ and the population share acquiring human capital, $\lambda_{t} \equiv\left(1-\tilde{a}_{t}^{*}\right)$, which satisfies Definition 1 is given by

$$
T_{t}=\Lambda\left(\lambda_{t}, A_{t}\right)=\frac{e}{1-\Omega\left(A_{t}\right) g\left(\lambda_{t}\right)}
$$


with $\Omega\left(A_{t}\right)=1 /\left(2^{1-\alpha} A_{t}\right)$, where $A_{t}=A_{t}^{\mathcal{H}} / A_{t}^{\mathcal{L}}$, and $g\left(\lambda_{t}\right)=\frac{\left(1-\left(1-\lambda_{t}\right)^{2}\right)^{1-\alpha}}{\left(1-\lambda_{t}\right)^{2-\alpha}}$. The equilibrium fraction of the population acquiring human capital, $\lambda_{t}$, implied by condition (7), is monotonically increasing in $T_{t}$. The higher the life expectancy, the more people will invest in the timeconsuming human capital acquisition. This first central result is in accordance with the available evidence documenting the fact that longevity facilitates the accumulation of human capital. Boucekkine et al. (2003) provide evidence on the early increase in adult longevity prior to the industrial revolution and its effects on literacy. Swanson and Kopecky (1999), Kalemli-Ozcan (2002) and Reis-Soares (2003), among others, present evidence for the effect of life expectancy on educational attainment, growth and fertility choice. ${ }^{16}$

A closer analysis of (7) reveals that the predicted relationship between longevity and human capital acquisition is non linear and S-shaped, i.e. it is stronger and more pronounced for intermediate values of $T$ and $\lambda \cdot{ }^{17}$ Intuitively, for low levels of life expectancy, the fraction of individuals getting educated, $\lambda$, is small. This is due to the fixed time cost involved with its acquisition, which prevents a large part of the population from receiving enough lifetime earnings to be worth the effort. In this situation, it takes sufficiently large increases in life expectancy to provide incentives for a significant fraction of individuals to become educated. On the other hand, when already a substantial share of the population acquires human capital, very large increases in $T$ are necessary to make even more individuals supply skilled instead of unskilled labor. Due to decreasing returns in both sectors, the marginal productivity of unskilled workers is relatively large when there are only few of them. This dampens the attractiveness of investing in human capital, even if life expectancy is very high. In this context, it is worth noting that the equilibrium relationship only depends on the relative level of TFP in both sectors, $A_{t}=A_{t}^{\mathcal{H}} / A_{t}^{\mathcal{L}}$. Note also that, even in the absence of constraints to longevity, there is a

\footnotetext{
${ }^{16}$ The positive effect of longevity on education is also emphasized by De la Croix and Licandro (1999), Lagerlof (2003), Weisdorf (2004) and Galor (2004). For further evidence on the effect of health and living conditions on education attainments, see Alderman et al. (2001), and Chakraborty (2004). In that respect, $T_{t}$ could be alternatively interpreted as "effective time" rather than longevity without affecting the main results, as for the present purposes longevity (the length of the available time spell) and health or living conditions (the quality of the available time) are technically the same.

${ }^{17}$ The S-shape of the equilibrium locus prevents corner solutions in human capital acquisition. This feature follows from Inada conditions but, as clarified below, it is not crucial for the results.
} 
maximum fraction $\underline{\lambda}$ of individuals investing in human capital, which increases with $A$. These findings can be summarized as

Proposition 1. [EqUilibrium ACQUisition of hUmAn CAPITAL] For any generation $t$ with $T_{t} \in[e, \infty)$, the equilibrium fraction of individuals acquiring human capital, $\lambda_{t}\left(T_{t}\right)$, is

(i) unique, implicitly defined by (7), and satisfies Definition 1;

(ii) an increasing, $S$-shaped function of life expectancy $T_{t}$, with zero slope for $T \longrightarrow e$ and $T \longrightarrow \infty$, and exactly one inflection point;

(iii) increasing in the relative productivity of the human capital intensive sector, $A_{t}$;

(iv) bounded from above by $\underline{\lambda}_{t}(A)<1$ with $\frac{\partial \underline{\lambda}_{t}(A)}{\partial A}>0, \lim _{A \rightarrow 0} \underline{\lambda}_{t}(A)=0, \lim _{A \rightarrow \infty} \underline{\lambda}_{t}(A)=1$.

\section{Life Expectancy}

Historical and demographic evidence suggests that the levels of human capital and economic development profoundly affect life expectancy. There is ample evidence that an increasing popular knowledge of the causes, propagation and treatment of common diseases, of the importance of hygiene and sanitation, as well as the availability of respective technologies, helped to increase life expectancy over time, see e.g. Mokyr (1993), Schultz (1999), and Easterlin (1999). Empirical findings suggest that income, wealth and the level of education affect mortality and health, see Mirovsky and Ross (1998) and Smith (1999). In particular, there is evidence that children's life expectancy increases with parents' human capital and education (Schultz, 1993 and 1999), and that the human capital intensive invention of new drugs increases life expectancy (see Lichtenberg, 1998, 2002, 2003 ).

We formalize this positive externality by making the simple assumption that life expectancy of generation $t$ increases in the fraction of the population of the previous generation $(t-1)$ that 
acquired human capital: ${ }^{18}$

$$
T_{t}=\Upsilon\left(\lambda_{t-1}\right)=\underline{T}+\rho \lambda_{t-1}
$$

where $\rho>0$ reflects the extent of the externality. ${ }^{19}$ This formulation implies that the positive link does not rely on scale effects. There is a biological limit to extending life expectancy implicitly contained in the specification of equation (8) since, by definition of $\lambda$ as a fraction, the lifetime duration is bounded from above and thus cannot be increased beyond a certain level. We take this as a commonly agreed upon empirical regularity (see also Vaupel, 1998). The minimum life expectancy without any individual acquiring human capital is given by $\underline{T}>e$. Hence, even with minimal longevity, the acquisition of human capital is feasible. The precise functional form of this relation entails no consequences for the main results, and a (potentially more intuitive) concave relationship would not change the main argument.

\section{Technological Progress}

The technological environment evolves endogenously. Technological improvements take place with the arrival of new generations of individuals in the form of new vintages, which are characterized by larger TFP. Technological progress depends on the stock of human capital and is biased towards the skill-intensive sector of production. This formulation combines two central features. Firstly, following Lucas (1988) and Romer (1990), human capital is the engine of growth through an externality on productivity. Secondly, as in Nelson and Phelps (1966), Acemoglu (1998), and Galor and Moav (2000), technical progress is biased in favor of human capital. Doms et al. (1997) provide empirical evidence supporting this view. These two features imply that the available stock of human capital in a given generation indirectly makes human

\footnotetext{
${ }^{18}$ Equivalently, life expectancy could be related to average or total human capital, see Boucekkine et al. (2002), or income, see Blackburn and Cipriani (2002), of the previous generation(s). If one accepts a positive effect of the level of human capital on aggregate income, this assumption is also consistent with evidence indicating that the aggregate income share spent on health care increases with aggregate income levels, see Getzen (2000) and Gerdtham and Jönsson (2000) and the references there for the respective evidence.

${ }^{19}$ In reality, individuals can effectively influence their own life expectancy. However, during early phases of development, individuals lacked a detailed knowledge about which factors and activities are detrimental or beneficial for longevity, and beneficial factors, such as leisure, were simply not available. An explicit consideration of a positive correlation between an individual's life expectancy and his level of education would reinforce the results.
} 
capital more profitable to acquire for future generations. Since only the relative strength of productivity growth in both sectors is relevant for the argument of the paper, there is no loss in constraining the productivity effect to the $\mathcal{H}$-sector. Hence, for simplicity and without loss of generality, we normalize $A_{t}^{\mathcal{L}}=1$ such that $A_{t}=A_{t}^{\mathcal{H}}$. In particular,

$$
\frac{A_{t}-A_{t-1}}{A_{t-1}}=F\left(\lambda_{t-1}, A_{t-1}\right)=\delta H_{t-1}\left(\lambda_{t-1}\right) A_{t-1},
$$

where $\delta>0 .{ }^{20}$ This implies that the (relative) productivity of a given vintage, $A_{t}$, increases with the level of the human capital of the generation using the previous vintage, $H_{t-1}$, which is a function of the share of skilled people in the parent generation $\lambda_{t-1}$, as well as with the level of productivity already achieved at that stage, $A_{t-1}$.

Note that there are no scale effects involved in this specification. The crucial assumption for what follows is the relation between TFP and the share of the previous generation $\lambda_{t-1}$ investing in human capital. This specification emphasizes the particular role of human capital for the accumulation of knowledge and thus for technological progress. The specific functional form has little impact, since any specification implying a positive correlation between technological progress $\left(A_{t}-A_{t-1}\right) / A_{t-1}$ and $H_{t-1}$ would yield qualitatively identical results.

\section{The Process of Development}

This section presents the dynamic system and analyzes the evolution of the economy.

\section{A The Dynamic System}

The solution of the model allows to characterize the process of development as the interplay of individually rational behavior and macroeconomic externalities. The global dynamics of the economy are fully determined by the trajectories of life expectancy $T_{t}$, the fraction of the

\footnotetext{
${ }^{20}$ This specification follows Romer (1990). A more flexible specification adopted from Jones (2001) is used in the simulations below and leaves the qualitative results unchanged. In general, both types of labor can have a positive intertemporal effect on total factor productivity of both sectors, as long as the technological externality is biased towards the human capital intensive sector. In the simulations presented below, we actually allow total factor productivity in the sector using unskilled labor intensively to grow as well, reflecting the historical fact that agricultural productivity also increased as productivity in other sectors went up, e.g. during the industrial revolution, see Streeten (1994).
} 
population acquiring human capital $\lambda_{t}$, and productivity $A_{t}$. We therefore characterize the dynamic development of the economy by studying the evolution of these key variables over generations. The dynamic path of the economy is fully described by the infinite sequence $\left\{\lambda_{t}, T_{t}, A_{t}\right\}_{t \in[0,1,2, \ldots, \infty)}$, resulting from the evolution of the three dimensional, nonlinear discrete first-order dynamic system derived from equations (7), (8), and (9). For illustrative purposes, we first analyze the behavior of the economy by looking at the dynamic adjustment of human capital and life expectancy conditional on the value of the productivity $A$. In particular, we consider the reduced conditional system given by the inverse of the $\mathrm{S}$-shaped locus $T_{t}=\Lambda\left(\lambda_{t}, A\right)$ resulting from the labor market equilibrium condition (7), $\lambda_{t}=\Lambda^{-1}\left(T_{t}, A\right)$, and by the locus $T_{t}=\Upsilon\left(\lambda_{t-1}\right)$ representing the intergenerational externality on life expectancy given by (8),

$$
\left\{\begin{array}{l}
\lambda_{t}=\Lambda^{-1}\left(T_{t}, A\right) \\
T_{t}=\Upsilon\left(\lambda_{t-1}\right)
\end{array} .\right.
$$

This system delivers the dynamics of human capital formation and life expectancy for a given level of technology $A>0$. From the previous discussion we know that the first equation of the conditional system is defined for $T \in[e, \infty)$. Any steady state of the conditional system is characterized by the intersection of the two loci $\Lambda(A)$ and $\Upsilon$ :

Definition 2. [Steady State Equilibrium of the Conditional Dynamic System] $A$ steady state equilibrium of the dynamic system $(10)$ is a vector $E^{c}(A) \equiv\left\{\lambda_{A}^{c}, T_{A}^{c}\right\}$ with $\lambda_{A}^{c} \in[0,1]$ and $T_{A}^{c} \in[e, \infty)$, such that, for any $A \in(0, \infty): \lambda_{A}^{c}=\Lambda^{-1}\left(T_{A}^{c}, A\right)$ and $T_{A}^{c}=\Upsilon\left(\lambda_{A}^{c}\right)$. The associated equilibrium aggregate levels of unskilled and skilled labor are denoted by $L_{A}^{c}$ and $H_{A}^{c}$.

The system (10) displays at least one and, due to the S-shape of $\Lambda(A)$, at most three steady state equilibria $E^{c}(A) \equiv\left\{\lambda_{A}^{c}, T_{A}^{c}\right\}$, indexed by $c=L, u, H$. These steady state equilibria exhibit different properties. Low-type equilibria, denoted as $E^{L}(A)$, are characterized by low life expectancy $T_{A}^{L}$, and a small share of the population acquiring human capital $\lambda_{A}^{L}$. The locus $\Lambda(A)$ is locally concave at $\lambda_{A}^{L}$. High-type equilibria, denoted by $E^{H}(A)$, on the other hand, are characterized by a relatively large fraction of skilled individuals in the population $\lambda_{A}^{H}$, and high life expectancy $T_{A}^{H}$. Moreover, the locus $\Lambda(A)$ is locally convex at $\lambda_{A}^{H}$. The third type of equilibria, denoted $E^{u}(A)$, is unstable. Strictly positive amounts of both skilled and unskilled labor are supplied in any steady state. These findings are summarized in 
acquisition, is large. In this case, the conditional system is characterized by a unique dynamic equilibrium of type $E^{L}$ with low life expectancy and a small fraction of individuals acquiring human capital. This situation is depicted in Figure 4(a). During this early stage of development, the feedback effects between longevity and productivity are very small. Nonetheless, over the course of generations, productivity growth makes investing in education more profitable for everybody, and life expectancy increases slowly. Graphically, the locus $\Lambda(A)$ slowly shifts downwards as generations pass. Eventually, $\Lambda(A)$ exhibits three intersections with $\Upsilon$, the locus representing the intergenerational externality on life expectancy. Steady states of type $E^{u}$ and $E^{H}$ emerge in addition to $E^{L}$ but the economy remains trapped in the area of attraction of the $L$-type equilibria, as in Figure 4(b). As generations pass, the dynamic equilibrium induced by initially low life expectancy moves along $\Upsilon$, exhibiting minor improvements in life expectancy $T$ and aggregate human capital formation $\lambda$. The consecutive downward shifts of $\Lambda(A)$, however, eventually lead to a situation in which the $L$-type equilibrium lies in the tangency of the two curves, and becomes unstable, as shown in Figure 4(c). Already the following generation faces a life expectancy that is large enough to induce a substantially larger fraction to acquire human capital. At this point, there exists a unique $E^{H}$ steady state, as displayed in Figure 4(d). A period of rapid development is triggered, during which life expectancy and the share of individuals acquiring human capital grow rapidly: a transition in living conditions and the economic environment occurs similar to that experienced during the industrial revolution. It is important to note that the phase of sluggish development preceding the rapid transition could be arbitrarily long, depending on the parameters governing the process of technological innovation. The phase of fast development lasts for a few consecutive generations until life expectancy converges to its (biologically determined) upper bound $\rho+\underline{T}$, which is never achieved. Even though the fraction of the population acquiring human capital keeps growing, some small fraction of the population still supplies unskilled labor.

The following proposition summarizes these global dynamics. ${ }^{23}$ The evolution of the system is characterized by the sequence of population shares acquiring human capital, life expectancies and productivity levels $\left\{\lambda_{t}, T_{t}, A_{t}\right\}_{t \in[0,1,2, \ldots, \infty)}$.

\footnotetext{
${ }^{23} \mathrm{~A}$ technical version of the proposition is provided in the appendix.
} 


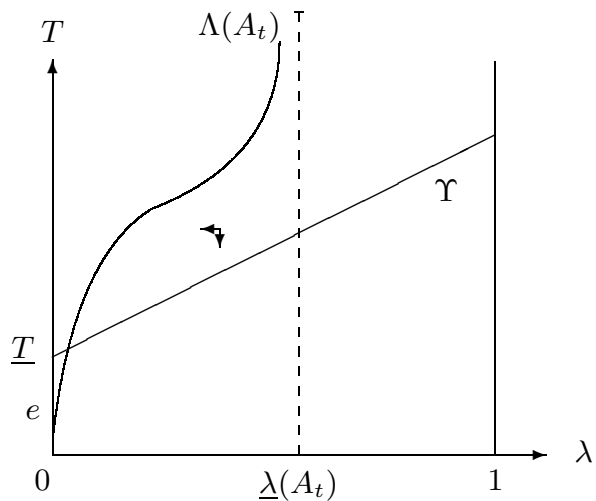

(a)

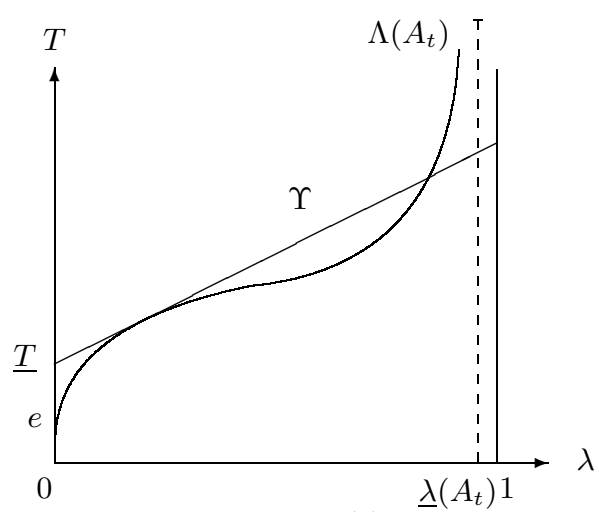

(c)

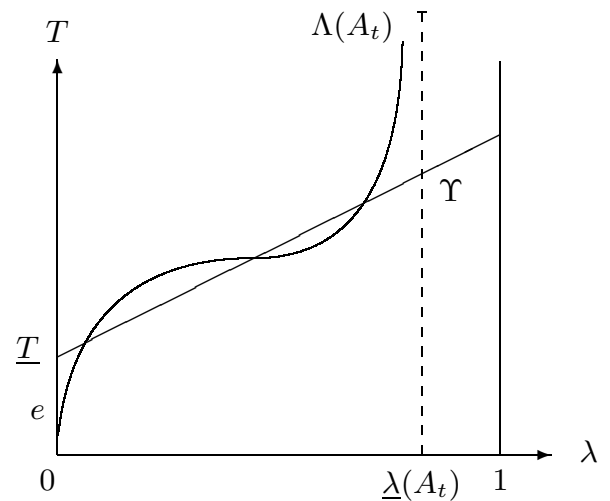

(b)

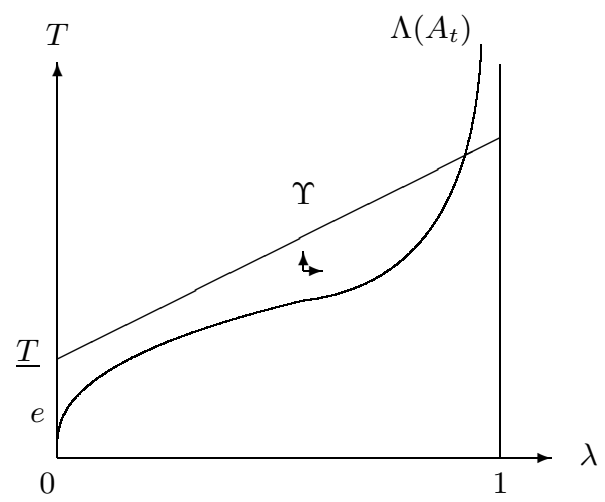

(d)

Figure 4: The Process of Development

Proposition 3. [Development Path of the Economy] An economy with sufficiently low $A$ and sufficiently large e passes through the following phases of development: (i) a (potentially very long) period of sluggish growth (a) in the area of attraction of a sequence of unique $L$ type equilibria, (b) trapped in the area of attraction of L-type equilibria despite the simultaneous existence of $H$-type equilibria; (ii) a rapid transition towards a sequence of $H$-type equilibria; (iii) a phase of sustained growth in the area of attraction of $H$-type equilibria.

It is important to note that the actual trajectory of the system depends on the initial conditions and cannot be characterized precisely in general. Proposition 3 in fact states that the system moves generation by generation in the area of attraction of the locally stable conditional state $E^{L}$ during phase $(i)$. In phases $(i i)$ and $(i i i)$, the system converges to a series of globally stable steady states $E^{H}$. At this point, it is worth noting that the fact that the equilibrium fractions of both types of labor are strictly positive, and that $\Lambda(A)$ is S-shaped, follows from Inada 
conditions. Even if $\alpha=1$, the same dynamic pattern of development would arise, however. ${ }^{24}$ In that case, the transition to $E^{H}$ would require an exogenous technological change, since during the phase of stagnancy prior to the transition no individual would find it optimal to acquire human capital. In historical terms, the model therefore exemplifies the different stages of development. $^{25}$ The inevitability of the transition to $E^{H}$-equilibria is driven by the formulation of technological progress in the tradition of endogenous growth theory. An alternative view of technological progress with stochastic elements, such as destruction of knowledge, forgetting and non-continuous, periodic improvements, could imply different predictions about the inevitability of the industrial revolution. ${ }^{26}$

\section{A Simulation of the Dynamic Evolution}

This section presents a simulation of the model to illustrate the mechanism described before and its capability to replicate the patterns of long-term development. We simulate the model using parameters reflecting empirical findings where possible. However, note that these simulations are not to be understood as a calibration exercise. ${ }^{27}$

The evolution of $T$ and $\lambda$ is depicted in Figures 5(b) and 5(c), respectively. Initially, life expectancy is quite low for a very long period of time. Its increase is continuous but barely detectable. At a certain point (around 1760) a period of rapid growth in average life expectancy begins. Within just a few generations, life expectancy increases from mid-20 to over 60, then

\footnotetext{
${ }^{24}$ The same is true for any concave production function that does not imply Inada conditions.

${ }^{25}$ Europe could be thought of as being trapped in a sequence of $E^{L}$ equilibria during ancient times and the Middle Ages. At some point during the late 18th century development took off, as the multiplicity of equilibria vanished. However, one could also think that, for example, African economies are still trapped today in dynamic equilibria characterized by low life expectancy and low levels of human capital acquisition (exemplified by e.g. literacy).

${ }^{26}$ For example, one could easily introduce random shocks affecting life expectancy and/or the stock of human capital in the economy, representing events exogenous to the economic system such as wars. In this case the links between generations through human capital are weakened or broken, which might prolong or even completely prevent the take-off characterized above. A much more thorough discussion of the role of human capital acquisition and knowledge for the economic transition is provided by Mokyr (2002, 2004).

${ }^{27}$ For the illustration, we simulate the economy over a horizon of 780 years, starting in year 1250. Clearly, using an appropriate parametrization, the model is capable of generating a deliberately long period of stagnant development before the phase transition. The parameters used in the simulation are reported in Appendix B.
} 


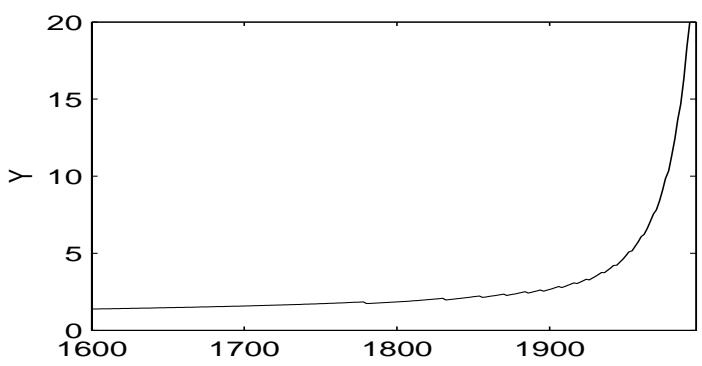

(a) Income per capita

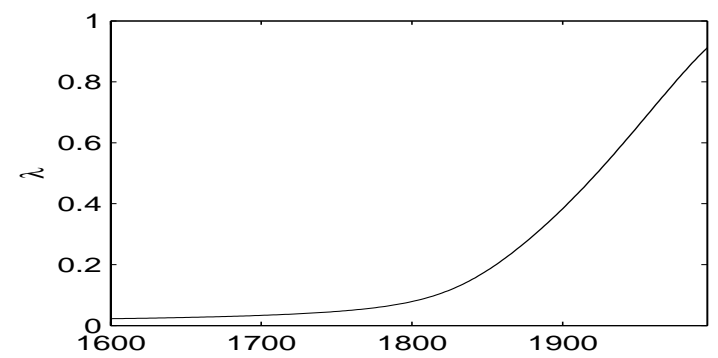

(c) Fraction of Educated Individuals

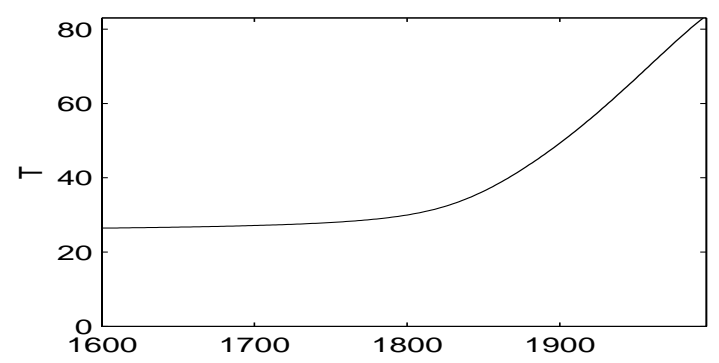

(b) Life Expectancy

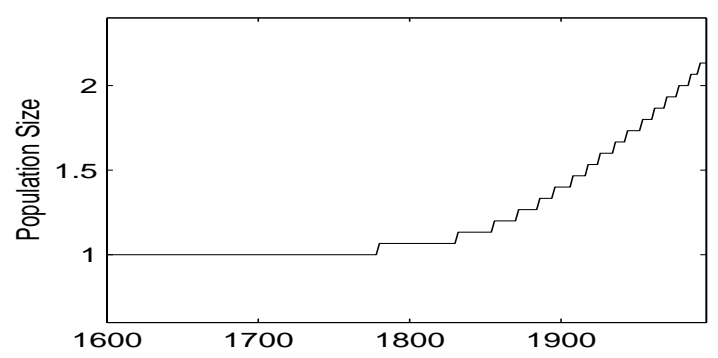

(d) Population Size

Figure 5: An Illustrative Simulation of the Development Process

its growth slows down again. Just when life expectancy takes off, more and more people begin to acquire human capital. ${ }^{28}$ However, eventually also this process slows down, as the share of educated people exceeds roughly three quarters of the population. Due to the permanent growth in TFP, the aggregate stock of human capital keeps increasing, even after the transition, albeit at ever lower rates.

The dynamics of aggregate income and population size are shown in Figures 5(a) and 5(d), respectively. After initially growing only very slowly, aggregate income takes off and keeps growing rapidly, even when growth in $T$ and $\lambda$ ebbs away. Despite permanent growth in income generated in sector $\mathcal{L}$, development is mainly driven by progress in sector $\mathcal{H}$. As life expectancy increases, more and more generations populate the economy at the same time. As a consequence, the population grows substantially even though individual fertility behavior is assumed

\footnotetext{
${ }^{28}$ This is reflected in a rapid decrease of the ability threshold for becoming educated.
} 
to be constant and the same throughout generations. ${ }^{29}$ Eventually, population size stabilizes. ${ }^{30}$ Together, the simulations demonstrate the model's capability of explaining the simultaneous endogenous transition in different dimensions of human life documented in the introduction.

\section{Concluding Remarks}

The history of the Western world was characterized by a lengthy period of stagnation in economic conditions, life expectancy, skills and population size, which was suddenly followed by a period of fast and dramatic changes in all these dimensions. This paper presents a unified theory that allows to explain these historical patterns by explicitly taking the interactions between living conditions in terms of longevity and economic factors into account. Both economic development and changes in life expectancy are modelled as endogenous processes. An implication of this view is that even during the apparently stagnant environment before the transition, economic factors and health conditions affected one another.

Wages, which are determined by productivity, and life expectancy are the crucial variables in the individual education decision. In turn, this education decision has implications for the education decisions of future generations, both through life expectancy and productivity changes. Thus, advances in technological progress, human capital formation and longevity potentially reinforce each other. However, the costs of acquiring skills are prohibitively high for large parts of the population in an undeveloped environment, that is when life expectancy and productivity are low. Only once the entire system is sufficiently developed does the positive feedback loop have enough momentum to overcome the retarding effects of costs for human capital formation. We analytically characterize the resulting development path, which exhibits a long period of economic stagnation and poor living conditions, followed by a relatively short period of dramatic improvements in all these dimensions.

In order to isolate the role of the individual human capital investment problem for the

\footnotetext{
${ }^{29}$ This is consistent with the argument and evidence put forward by Johnson (2000), who claims that population growth in the developed countries in the 19th Century was almost entirely driven by higher life expectancy rather than increased fertility.

${ }^{30}$ The non-smooth, jagged development of the population size follows from the fact that the number of populations alive at each point in time is discrete.
} 
dynamics of the system, we explicitly rule out features like scale effects related to population size or the stock of human capital, the presence of fixed factors of production, like land, or the existence of consumption subsistence levels as driving factors for the transition. The mechanism presented in this paper is able to reproduce the observed patterns of long-term development without the need of relying on exogenous events and strict temporal causalities. There is thus no need for identifying a driving shock that triggered the transition. By simulating the model for illustration purposes, we show that the long-run behavior of key indicators of development like income, income growth, productivity, life expectancy, and population size implied by the model is in line with empirical evidence and stylized facts. 


\section{A Appendix: Proofs}

For notational simplicity, denote in the following $\widetilde{a}^{*}$ simply as $a$. Also, as long as there is no danger of confusion, we suppress the subscripts ' $t$ ' for generation $t$ for notational convenience (e.g. $T_{t}\left(a_{t}\right)=T(a)$, etc.).

\section{Proposition 1 [Optimal Acquisition of Human Capital]:}

Proof. Using equations (2), (5) and (6), one can derive condition (7), which satisfies the definition 1 for a labor market equilibrium. Recall that $g(a) \equiv\left(1-a^{2}\right)^{1-\alpha} a^{\alpha-2}$ and $\Omega=1 /\left(2^{1-\alpha} A\right)$. Using standard calculus, we get,

$$
T^{\prime}(a)=\frac{e g^{\prime}(a) \Omega}{[1-g(a) \Omega]^{2}}
$$

and

$$
g^{\prime}(a)=-g(a)\left[\frac{2(1-\alpha) a^{2}+(2-\alpha)\left(1-a^{2}\right)}{\left(1-a^{2}\right) a}\right] \equiv-g(a) f(a)<0 .
$$

Since $T>0$, and since $g^{\prime}(a)<0$, the support of $a$ is restricted to those values of $a$ such that $1-\Omega(A) g(a)>0$. This implies a lower bound $\underline{a}(A): g(\underline{a}(A)) \Omega(A)=1$. Note also that $T(\underline{a}(A))=\infty$. Claim (iv) follows immediately.

Next, note that $T^{\prime}(a)<0 \forall a \in[\underline{a}(A), 1]$, hence $T(a)$ is invertible in $a \in[\underline{a}(A), 1]$. Also $T(a) \geq e \forall a \in[0,1]$, so the inverse function $a(T)$ is strictly monotonically decreasing for all positive $T$. Using (12) and $g^{\prime \prime}(a)=g\left(f(a)^{2}-f^{\prime}(a)\right)$, we get

$T^{\prime \prime}(a)=\frac{e \Omega g^{\prime \prime}(a)[1-g(a) \Omega]+2 e\left[g^{\prime}(a)\right]^{2} \Omega^{2}}{[1-g(a) \Omega]^{3}}=\frac{e \Omega g(a)\left(f(a)^{2}-f^{\prime}(a)\right)[1-g(a) \Omega]+2 e[g(a) f(a)]^{2} \Omega^{2}}{[1-g(a) \Omega]^{3}}$.

The necessary condition for an inflection point is $T^{\prime \prime}(a)=0$ or,

$$
\begin{aligned}
g(a)\left(f^{\prime}(a)-f(a)^{2}\right)[1-g(a) \Omega] & =2[g(a) f(a)]^{2} \Omega \\
\left(f^{\prime}(a)-f(a)^{2}\right) & =2\left[\frac{g(a) \Omega}{1-g(a) \Omega}\right] f(a)^{2} \\
-2 \alpha a^{2}\left(1-a^{2}\right)-\left(2-\alpha-\alpha a^{2}\right)\left(1-3 a^{2}\right)-\left(2-\alpha-\alpha a^{2}\right)^{2} & =2\left[\frac{g(a) \Omega}{1-g(a) \Omega}\right]\left(2-\alpha-\alpha a^{2}\right)^{2} \\
-2 \alpha b(1-b)-(2-\alpha-\alpha b)(1-3 b)-(2-\alpha-\alpha b)^{2} & =2\left[\frac{h(b) \Omega}{1-h(b) \Omega}\right](2-\alpha-\alpha b)^{2} \\
(\text { LHS }) & =(\text { RHS })
\end{aligned}
$$

where we denote $a^{2} \equiv b$ and $\underline{b} \equiv \underline{a}^{2}$ and $g(a)=h(b)$. The inflection point is unique since the RHS is a strictly decreasing continuous function in $b \in(\underline{b}(A), 1)$, taking infinite value at $\underline{b}(A)$ and zero value at $b=1$, while the $L H S$ is a quadratic and strictly concave function taking negative value at $b=0$ and positive value at $b=1$. Therefore, by applying the intermediate value theorem, there exists a unique $b_{A}^{I} \in(\underline{b}(A), 1)$, and correspondingly, a unique $a_{A}^{I} \in(\underline{a}(A), 1)$, such that $T^{\prime \prime}\left(a_{A}^{I}\right)=0$. Furthermore, $T(a)$ is convex for low $a \in(\underline{a}(A), 1)$, and concave for large $a \in(\underline{a}(A), 1)$. Finally, inspection of $T^{\prime}(a)$ reveals that the function $T$ has infinite slope both at $a=\underline{a}(A)$ and $a=1 .{ }^{31}$

\section{Proposition 2 [Properties of Steady State Equilibria]:}

\footnotetext{
${ }^{31}$ Since $a=1-\lambda$, the function (7) is strictly increasing in $\lambda$, first concave and then convex with a vertical asymptote at $\underline{\lambda}(A)=1-\underline{a}(A)$, as in Figure 3 and infinite slope at $\lambda=0$.
} 
Proof. Consider the $T-a$ space. $(\boldsymbol{i})$ : the $\Upsilon$-locus is linear, with slope $-\rho, T(a=0)=\underline{T}+\rho$ and $T(a=1)=\underline{T}$. From the proof of Proposition 1 we know that, for any $A>0$, the locus $\Lambda(A)$ has a saltus at $\underline{a}$ as $\lim _{a \downarrow \underline{a}(A)} T_{t}(a, A)=\infty$, and that $\Lambda$ is monotonically decreasing $\forall a>\underline{a}(A)$. Since $T(1)=e \forall t$, and $e<\underline{T}$, hence $\Lambda(A)$ takes values above $\Upsilon$ at the extreme $a=\underline{a}(A)$ and below $\Upsilon$ at $a=1$. The intermediate value theorem insures at least one intersection for any given $A$. Any unique steady state equilibrium is therefore globally stable.

(ii): From Proposition 1, $\Lambda(A)$ has always a unique inflection point. Hence, the loci $\Lambda$ and $\Upsilon$ can intersect at most three times. Claim a) follows from the negative slopes of both loci that allow to rank steady states. Claims $(b)$ and $(c)$ : follow immediately from $(i)$, since at extreme equilibria $E^{H}(A)$ and $E^{L}(A), \Lambda(A)$ intersects $\Upsilon$ from above, which means that the system is locally stable, while the opposite is true for the intermediate equilibrium $E^{u}(A)$.

(iii): Using (i), note that any steady state is characterized by an interior solution with $a<1$, since $T(a=1)=e<\underline{T}$, which implies $H_{A}^{c}>0$ and $L_{A}^{c}>0$ for any $c=L, u, H$ and for any $A>0$.

\section{Proposition 3 [Development Path of the Economy]:}

We start by analyzing the evolution of technology. Using (9), express the level of relative TFP for generation $t$ as,

$$
A_{t}=\left(1+F\left(\lambda_{t-1}, A_{t-1}\right)\right) A_{t-1}=\left(\delta H_{t-1} A_{t-1}+1\right) A_{t-1} .
$$

Equation (14) is of the form $A_{t}=\left(c_{t-1}+1\right) A_{t-1}=d_{t-1} A_{t-1}$, where $d_{t-1}=\delta H_{t} A_{t-1}+1>1$ for any $t$, since from Proposition $2, H_{t}(A)>0$ for any $t$ and $\delta>0$. For any $A_{0}>0$, we can rewrite $A_{t}=\left(\prod_{i=1}^{t} d_{i-1}\right) A_{0}$, where $\left(\prod_{i=1}^{t} d_{i-1}\right)>1$ and $\lim _{t \longrightarrow \infty}\left(\prod_{i=1}^{t} d_{i-1}\right)=\infty$. This means that the process is autoregressive, positive monotonous and non stationary. Hence, $A_{t}$ is strictly increasing generation after generation, with $\lim _{t \rightarrow \infty} A_{t}=\infty$. Next, we show that for any $a$, technological progress induces larger human capital accumulation: by partial derivation of equation (7), $\frac{\partial T_{t}\left(a_{t}\right)}{\partial A_{t}}=-\frac{T_{t}\left(a_{t}\right)}{\left[1-\Omega\left(A_{t}\right) g\left(a_{t}\right)\right]} \frac{g\left(a_{t}\right)}{\Omega\left(A_{t}\right) A_{t}}<0 \forall a \in\left[\underline{a}\left(A_{t}\right), 1\right]$ implying that the locus $\Lambda(A)$ shifts downward $\forall a \in[0,1]$. Denote by $\Lambda^{\prime}(A) \equiv \partial T(a, A) / \partial a$ the function characterizing the slope of $\Lambda(A)$, while $\Lambda^{\prime \prime}(A) \equiv \partial^{2} T(a, A) / \partial a^{2}$ denotes the second derivative. From Proposition 1 , $\left|\Lambda^{\prime}(A)\right|$ is $\mathrm{U}$-shaped, takes infinite value at the extremes of the support $\{\underline{a}(A), 1\}$, and exhibits a unique global minimum at $a_{A}^{I}: \Lambda^{\prime \prime}\left(A, a_{A}^{I}\right)=0$. Also,

$$
\frac{\partial}{\partial A_{t}}\left|\frac{\partial T_{t}\left(a_{t}, A_{t}\right)}{\partial a_{t}}\right|=\frac{-e g_{t} f_{t}}{\left(1-g_{t} \Omega_{t}\right)^{3}}\left[1-g_{t} \Omega_{t}+2 \Omega_{t}\right] \frac{1}{2^{1-\alpha} A_{t}^{2}}<0 \quad \forall a \in\left[\underline{a}\left(A_{t}\right), 1\right] .
$$

implying that, $\forall a \in[\underline{a}(A), 1],\left|\Lambda^{\prime}(A)\right|$ shifts downward as $A$ increases. Also, $\lim _{A \longrightarrow 0} \underline{a}(A)=1$, $\lim _{A \longrightarrow \infty} \underline{a}(A)=0, \lim _{A \longrightarrow \infty}\left(\frac{\partial T(a, A)}{\partial a}\right)=0 \forall a \neq\{\underline{a}(A), 1\}$, and $\lim _{A \longrightarrow 0}\left|\left(\frac{\partial T(a, A)}{\partial a}\right)\right|=+\infty$, $\forall a \in[\underline{a}(A), 1]$. Therefore $\Lambda^{\prime}(A)$ eventually takes value zero in the interior of the bounded support as $A \longrightarrow \infty$, and $\Lambda(A)$ is almost vertical at $a=1$ (with infinite slope) as $A \longrightarrow 0$. Figure 6 plots $\left|\Lambda^{\prime}(A)\right|$ for different $A$. As $A$ increases, $\left|\Lambda^{\prime}(A)\right|$ shifts downwards. Hence, there exists a unique value $A^{0}$ and, correspondingly, a unique generation $t^{0}$, such that $\left|\Lambda^{\prime}\left(A^{0}, a_{A^{0}}^{I}\right)\right|=\rho$. For $A=A^{0}$, the loci $\left|\Lambda^{\prime}\right|$ and $\Upsilon^{\prime}=\rho$ in Figure 6 are tangent. Hence, $\left|\Lambda^{\prime}\left(A, a_{A}^{I}\right)\right| \stackrel{\gtrless}{<} \Longleftrightarrow A>A^{0}$. Since $\left|\Lambda^{\prime}(A)\right|$ is globally convex, by definition of $a_{A}^{I}$ as extremum (or from graphical inspection of Figure 6), for any $t \geq t^{0}$ there exist exactly two levels of $a, a_{A_{t}}^{1} \leq a_{A_{t}}^{I} \leq a_{A_{t}}^{2}$, where $a_{A_{t}}^{1}$ lies in the convex and $a_{A_{t}}^{2}$ in the concave part of $\Lambda(A)$, such that $\left|\Lambda^{\prime}\left(A_{t}, a_{A_{t}}^{1}\right)\right|=\rho=\left|\Lambda^{\prime}\left(A_{t}, a_{A_{t}}^{2}\right)\right|$.

Proposition 2 proves existence of at least one equilibrium of the system (10). For any generation $t<t_{0}$, the equilibrium is unique since $\left|\Lambda^{\prime}\left(A_{t}\right)\right|>\rho \forall a \in[\underline{a}(A), 1]$ and the loci $\Lambda\left(A_{t}\right)$ and $\Upsilon$ necessarily intersect only once. For $t \geq t^{0}$, multiple equilibria may arise if $\Lambda(A)$ is flatter than $\Upsilon$ in some range of the support. Thus, at $t^{0}$ two scenarios are possible depending on the nature of the unique equilibrium. If $\Lambda\left(A^{0}, a_{A^{0}}^{I}\right)<\Upsilon\left(a_{A^{0}}^{I}\right)$, the unique equilibrium is of type 


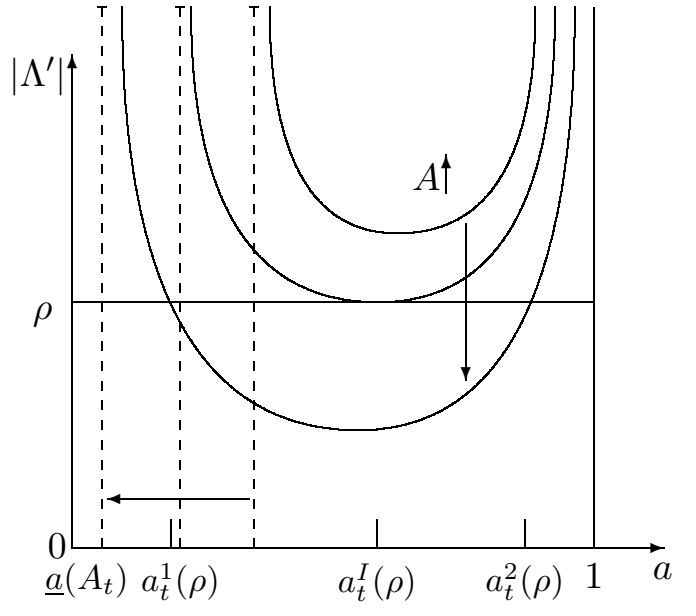

Figure 6: Emergence of Multiple Equilibria

$H$ since, by definition of $a_{A}^{I}$ as inflection point, the two loci $\Upsilon$ and $\Lambda$ intersect in the convex part of $\Lambda(A)$. This is the case if and only if the concave part of $|\Lambda(A)|$ is sufficiently small, which is true if the fixed cost of acquiring human capital $H, e$ is sufficiently small. In this case, nothing prevents agents from acquiring human capital from early stages on, and the economy develops smoothly as $A$ increases overtime. In the other scenario, $\Lambda\left(A_{0}, a_{A^{0}}^{I}\right) \geq \Upsilon\left(a_{A^{0}}^{I}\right)$, so the unique equilibrium for generation $t^{0}$ is of type $L$. In this case, acquiring $H$ is individually costly in an underdeveloped economy, or, equivalently, $e$ is sufficiently large to generate a development trap. The economy is characterized by a lengthy sequence of $L$-equilibria which is eventually followed by a development process as described in Proposition 3. Proposition 3 in the text is formally equivalent to:

Proposition 3. Consider an economy with e sufficiently large, so that $\forall A \leq A^{0}$, the system (10) is characterized by a unique steady state equilibrium of type L. There exist $A^{0}<A^{1}<A^{2}<\infty$ such that the system (10) is characterized by:

(i) a unique type $L$ equilibrium $\forall A_{t} \leq A^{1}$;

(ii) two steady states $E^{u}\left(A^{1}\right)$ and $E^{L}\left(A^{1}\right)$ at $A_{t}=A^{1}$;

(iii) three steady states: $E^{H}\left(A_{t}\right), E^{u}\left(A_{t}\right)$ and $E^{L}\left(A_{t}\right) \forall A_{t} \in\left(A^{1}, A^{2}\right)$;

(iv) two steady states $E^{H}\left(A^{2}\right)$ and $E^{u}\left(A^{2}\right)$ at $A_{t}=A^{2}$;

(v) a unique $H$-type equilibrium $\forall A_{t}>A^{2}$.

There exists a unique generation $t^{2}: \forall t \leq t^{2}$ the economy is characterized by a sequence of $L$-type equilibria reflecting (i)-(iv), while $\forall t>t^{2}$ the economy is characterized by a sequence of $H$-type equilibria, reflecting ( $v)$.

Proof. Since, as previously proved, $A_{t}$ strictly increases in $t$, we can determine the dynamics of the system by the position of $\Lambda\left(A_{t}, a_{t}^{I}\right), \Lambda\left(A_{t}, a_{t}^{1}\right)$, and $\Lambda\left(A_{t}, a_{t}^{2}\right)$ with respect to the corresponding values of the $\Upsilon$-locus. Consider first claims (i) and $(v)$. By construction, at $t^{0}$ the steady state is $L$-type. As $A \rightarrow \infty$, there is a unique equilibrium with $a_{t}^{H}$ close to zero since $\lim _{A \rightarrow \infty} \underline{a}(A)=0$ and $\Lambda(A, \underline{a})=\infty$. Given the previous discussion regarding $\partial\left|\Lambda^{\prime}(A, a)\right| / \partial A$, the locus $\Lambda(\infty, a)$ exhibits infinite value at $a=0$ and value $e$ elsewhere. Hence there must exist a generation $t^{2}: \forall t>t^{2}$ the $H$-type equilibrium is unique. Consider claims (ii), (iii) and (iv). $\Lambda(A, a)$ and $\left|\Lambda^{\prime}(A, a)\right|$ decrease monotonically with $A$. By continuity, there exists a level $A^{1}$ such that $\Lambda\left(A^{1}, a_{A^{1}}^{1}\right)=\Upsilon\left(a_{A^{1}}^{1}\right)$ but $\Lambda\left(A^{1}, a_{A^{1}}^{2}\right)>\Upsilon\left(a_{A^{1}}^{2}\right)$ since $a_{A^{1}}^{2}$ lies in the concave part of $\Lambda(A)$. Consequently, for any $A>A^{1}: \Lambda\left(A, a_{A}^{1}\right)<\Upsilon\left(a_{A}^{1}\right)$. The same reasoning insures the 
existence of $A^{2}: \Lambda\left(A^{2}, a_{A^{2}}^{2}\right)=\Upsilon\left(a_{A^{2}}^{2}\right)$ and the fact that $\Lambda\left(A, a_{A}^{2}\right)<\Upsilon\left(a_{A}^{2}\right)$ for any $A>A^{2}$. Since $\Lambda(A, a)$ is continuous and monotonic in $a$, for any $A \in\left(A^{1}, A^{2}\right), \Lambda\left(A, a_{A}^{1}\right)<\Upsilon\left(a_{A^{1}}^{1}\right)$ and $\Lambda\left(A^{2}, a_{A^{2}}^{2}\right)>\Upsilon\left(a_{A^{2}}^{2}\right)$ there exists a unique level $a^{u}(A)$ which determines a locally unstable steady state of the system (10). Since both loci $\Lambda(A)$ and $\Upsilon$ are decreasing in $a$, the levels of $T$ and $a$ associated to any locally stable steady state change monotonically as generations $t$ pass. This follows from comparative statics in supermodular settings (or simple graphical inspection). An increase in $A$ shifts $\Lambda(A)$ down, increasing $T$ and decreasing $a$ associated to any locally stable equilibrium (the opposite is true for unstable ones).

Note that, since $A$ changes discretely as generations pass, it may be the case that not all the phases from (i) to ( $v$ ) are exactly realized. In particular, stages (ii) and (iv) with the system displaying exact tangency and two equilibria, may not realize if the discrete change in $A$ moves the system from one to three steady states within just one generation, namely if, for some $t$ : $A_{t}<A^{1}<A_{t+1}$ or $A_{t}<A^{2}<A_{t+1}$. Nonetheless, the global evolution of the system (10) necessarily follows the described phases with the full system evolving around an $L$-type locally stable steady state before an endogenous rapid transition to a globally stable steady state of type $H$.

\section{B Appendix: Simulation}

For the illustration, we simulate the economy over 390 generations. Interpreting every 2 years as the arrival of a new generation, this reflects roughly a horizon from year 1250 to 2030, which includes the industrial revolution. Parameter values and initial conditions used in the simulation are contained in Table 1. A maximal life expectancy of 90 years cannot be exceeded, while the minimum life expectancy is assumed to be 25 years, which is in line with Streeten (1994) who cites evidence that average life expectancy in central Europe was around 25 years before 1650 . The assumptions imply also that the total scope of extending life expectancy by research, medical inventions and the like is 65 years $(\rho)$. The fixed cost of acquiring human capital, $e$, is 15 years. Adopting a generalization of the specification of Romer (1990) similar to that by Jones (2001), technological improvements in both sectors are modelled as $\frac{A_{t}^{\mathcal{H}}-A_{t-1}^{\mathcal{H}}}{A_{t-1}^{\mathcal{H}}}=\delta^{\mathcal{H}} H_{t-1}^{\phi^{\mathcal{H}}}\left(A_{t-1}^{\mathcal{H}}\right)^{\chi^{\mathcal{H}}}$, and $\frac{A_{t}^{\mathcal{L}}-A_{t-1}^{\mathcal{L}}}{A_{t-1}^{\mathcal{L}}}=\delta^{\mathcal{L}} H_{t-1}^{\phi^{\mathcal{L}}}\left(A_{t-1}^{\mathcal{L}}\right)^{\chi^{\mathcal{L}}}$, respectively, where $\delta^{\mathcal{H}}, \delta^{\mathcal{L}}, \phi^{\mathcal{H}}, \phi^{\mathcal{L}}, \chi^{\mathcal{H}}$ and $\chi^{\mathcal{L}}$ are positive real numbers. Both sectors exhibit the same extent of decreasing returns to the stock of human capital $\alpha$. The assumption $\delta^{\mathcal{H}}>\delta^{\mathcal{L}}$ implies that TFP grows relatively faster in the $\mathcal{H}$-sector. Initially, TFP in both sectors is the same. ${ }^{32}$

Table 1: Parameter Values Used for Simulation

\begin{tabular}{cccccccc}
\hline \hline$\alpha$ & 0.5 & $\delta^{\mathcal{H}}$ & 0.025 & $\chi^{\mathcal{H}}$ & 0.5 & $e$ & 15.0 \\
$A_{0}^{\mathcal{H}}=A_{0}^{\mathcal{L}}$ & 1.0 & $\delta^{\mathcal{L}}$ & 0.01 & $\chi^{\mathcal{L}}$ & 0.6 & $\underline{T}$ & 25.0 \\
$\lambda_{0}$ & 0.005 & $\phi^{\mathcal{H}}$ & 0.55 & $\phi^{\mathcal{L}}$ & 0.45 & $\rho$ & 65.0 \\
\hline \hline
\end{tabular}

\footnotetext{
${ }^{32}$ In other settings, the relative productivity of skilled to unskilled sector, $A_{t}$ may initially decrease, reflecting the larger innovative dynamics of sector $\mathcal{L}$ during early stages of development, and delaying a widespread acquisition of human capital. However, since human capital is relatively more important for technological progress, the productivity in the skill-intensive sector eventually outruns that in the low-skill sector, so that relative productivity eventually increases and keeps increasing from this point on.
} 


\section{References}

Acemoglu, D. (1998): "Why Do Technologies Complement Skills? Directed Technical Change and Wage Inequality," Quarterly Journal of Economics, 113(4), 1055-1089.

Alderman, H., J. Behrman, V. Lavy, and R. Menon (2001): "Child Health and School Enrollment - A Longitudinal Analysis," Journal of Human Resources, 36, 185-205.

Blackburn, K., and G. P. Cipriani (2002): "A Model of Longevity, Fertility and Growth," Journal of Economic Dynamics and Control, 26, 187-204.

Boucekkine, R., D. De la Croix, and O. Licandro (2002): "Vintage Human Capital, Demographic Trends, and Endogenous Growth," Journal of Economic Theory, 104(2), 340375.

(2003): "Early Mortality Declines at the Dawn of Modern Growth," Scandinavian Journal of Economics, 105, 401-418.

Chakraborty, S. (2004): "Endogenous Lifetime and Economic Growth," Journal of Economic Theory, 116, 119-137.

Cipolla, C. M. (1969): Literacy and Development in the West. Penguin Books, Middlesex, England.

(1976): Before the Industrial Revolution: European Society and Economy 1000-1700. Routledge, London.

Croix, D. D. L., And O. Licandro (1999): "Life Expectancy and Endogenous Growth," Economics Letters, 65, 255-263.

Doepke, M. (2004): "Accounting for Fertility Decline During the Transition to Growth," Journal of Economic Growth, 9(3), 347-383.

Doms, M., T. Dunne, And K. Troske (1997): "Workers, Wages, and Technology," Quarterly Journal of Economics, 112(1), 253-290.

Easterlin, R. A. (1999): "How Beneficient is the Market? A Look at the Modern History of Mortality," European Review of Economic History, 3, 257-294. 
Floud, R., And D. McCloskey (1994): The Economic History of Britain Since 1700. Cambridge University Press, Cambridge.

Galor, O. (2004): "From Stagnation to Growth: Unified Growth Theory," in Handbook of Economic Growth, forthcoming, ed. by P. Aghion, and S. Durlauf. Elsevier Science B.V., Amsterdam.

Galor, O., And O. Moav (2000): "Ability-Biased Technological Transition and Economic Growth," Quarterly Journal of Economics, 115(2), 469-497.

(2002): "Natural Selection and the Origin of Economic Growth," Quarterly Journal of Economics, 117(4), 1133-92.

Galor, O., and D. N. Weil (2000): "Population, Technology, and Growth: From Malthusian Stagnation to the Demographic Transition and Beyond," American Economic Review, 90(4), $807-828$.

Gerdtham, U., And B. Jönsson (2000): "International Comparisons of Health Expenditure: Theory, Data and Econometric Analysis," in Handbook of Health Economics, ed. by A. Culyer, and J. Newhouse, chap. 1, pp. 11-53. Elsevier, Amsterdam.

Getzen, T. E. (2000): "Health Care Is an Individual Necessity and a National Luxury: Applying Multi-Level Decision Models to the Analysis of Health Care Expenditures," Journal of Health Economics, 19, 259-270.

Goodfriend, M., And J. McDermott (1995): "Early Development," American Economic Review, 85(1), 116-133.

Hansen, G. D., And E. C. Prescott (2002): "Malthus to Solow," American Economic Review, 92(4), 1205-1217.

Hassler, J., And J. Rodriguez-Mora (2000): "Intelligence, Social Mobility, and Growth," American Economic Review, 90(4), 888-908.

Hazan, M., And B. Berdugo (2002): "Child Labor, Fertility, and Economic Growth," Economic Journal, 112, 810-828. 
Hazan, M., And H. ZoAbi (2004): "Does Longevity Cause Growth?," mimeo, Hebrew University.

Johnson, G. D. (2000): "Population, Food and Knowledge," American Economic Review, $90(2), 1-14$.

Jones, C. I. (2001): "Was an Industrial Revolution Inevitable? Economic Growth Over the Very Long Run," Advances in Macroeconomics, 1(2).

Kalemli-Ozcan, S. (2002): "Does Mortality Decline Promote Economic Growth?," Journal of Economic Growth, 7(4), 411-439.

Kogel, T., And A. Prskawetz (2001): "Agricultural Productivity Growth and the Escape from Malthusian Trap," Journal of Economic Growth, 6, 337-357.

Komlos, J., And M. Artzouni (1990): "Mathematical Investigations of the Escape from the Malthusian Trap," Mathematical Population Studies, 2(4), 269-287.

Kremer, M. (1993): "Population Growth and Technological Change: One Million B.C. To 1990," Quarterly Journal of Economics, 108(3), 681-716.

Lagerlof, N.-P. (2003): "From Malthus to Modern Growth: The Three Regimes Revisited," International Economic Review, 44(2), 755-777.

LichtenberG, F. R. (1998): "Pharmaceutical Innovation, Mortality Reduction, and Economic Growth," NBER Working Paper, 6569.

(2002): "Sources of U.S. Longevity Increase, 1960-1997," NBER Working Paper, 8755. (2003): "The Impact of New Drugs Launches on longevity: Evidence from Longitudinal, Disease-Level Data from 52 Countries, 1982-2001," NBER Working Paper, 9754.

LucAs, R. E. (1988): "On the Mechanics of Economic Development," Journal of Monetary Economics, 22, 3-42.

(2002): Industrial Revolution, Past and Future. Harvard University Press, Cambridge, Massachusetts. 
Maddison, A. (1991): Dynamic Forces in Capitalist Development: A Long-Run Comparative View. Oxford University Press, Oxford.

Magnac, T., and G. Postel-Vinay (1997): "Wage Competition Between Agriculture and Industry in Mid-Nineteenth Century France," Explorations in Economic History, 34(1), 1-26.

Malcomson, J. M. (1975): "Replacement and the Rental Value of Capital Equipment Subject to Obsolescence," Journal of Economic Theory, 10(1), 24-41.

Mirovsky, J., And C. Ross (1998): "Education, Personal Control, Lifestyle and Health - A Human Capital Hypothesis," Research on Ageing, 20, 415-449.

MoAv, O. (2005): "Cheap Children and the Persistence of Poverty," Economic Journal, forthcoming, 114 .

Mokyr, J. (1993): "Technological Progress and the Decline of European Mortality," American Economic Review, 83(2), 324-330.

- (2002): The Gifts of Athena. Princeton University Press, Princeton.

(2004): "Long-Term Economic Growth and the History of Technology," in Handbook of Economic Growth, forthcoming, ed. by P. Aghion, and S. Durlauf. Elsevier Science B.V., Amsterdam.

Nelson, R., And E. Phelps (1966): "Investment in Humans, Technological Diffusion, and Economic Growth," American Economic Review, 56(2), 69-75.

Reis-SoAres, R. (2003): "Mortality Reductions, Educational Attainment, and Fertility Choice," mimeo, University of Maryland.

Romer, P. M. (1990): "Endogenous Technological Change," Journal of Political Economy, 98(5), S71-S102.

Schofield, R. S. (1973): "Dimensions of Illiteracy, 1750-1850," Explorations in Economic History, 10(4), 437-454.

Schultz, P. T. (1993): "Mortality Decline in the Low-Income World: Causes and Consequences," American Economic Review, 83(2), 337-342. 
(1999): "Health and Schooling Investments in Africa," Journal of Economic Perspectives, 13(3), 67-88.

Smith, J. P. (1999): "Healthy Bodies and Thick Wallets: The Dual Relation Between Health and Economic Status," Journal of Economic Perspectives, 13(2), 145-166.

Streeten, P. (1994): "Human Development: Means and Ends," American Economic Review, $84(2), 232-237$.

Swanson, C. E., And K. J. Kopecky (1999): "Lifespan and Output," Economic Inquiry, $37(2), 213-225$.

Vaupel, J. W. (1998): "Demographic Analysis of Aging and Longevity," American Economic Review, 88(2), 242-247.

Weisdorf, J. (2004): "From Stagnation to Growth: Revisiting Three Historical Regimes," Journal of Population Economics, 17(3), 455-472.

West, E. (1978): "Literacy and the Industrial Revolution," Economic History Review, 31(4), 369-383.

Www.Mortality.Org (2002): "Human Mortality Database," provided by University of California, Berkeley, and Max Planck Institute for Demographic Research, downloaded Nov. 11, 2002. 